https://doi.org/10.48009/1_iis_2006_278-283

\title{
IMPLEMENTING ERP SOFTWARE INTO BUSINESS SCHOOL CURRICULUM: IT IS MORE COMMON, LESS DIFFICULT AND MORE IMPORTANT THAN YOU MAY THINK
}

\author{
John R. Willems, Eastern Illinois University, jrwillems@ eiu.edu \\ Saifur Bhuiyan, Eastern Illinois University, sbhuiyan@ eiu.edu
}

\begin{abstract}
Enterprise Resource Planning (ERP) software has become so pervasive in large and medium sized businesses that there exists a growing need for implementing it into the business curriculum at universities. This study discusses the results of a survey of AACSB accredited School of Business in the USA to determine the frequency of ERP integration into business classes, which ERP modules were more popularly used by business schools, and the degree of difficultly experienced while implementing ERP into the business curriculum. This research found that ERP is commonly being integrated into business classes and that these implementations are less complicated than you may have thought possible.
\end{abstract}

Keywords: Enterprise Resource Planning, ERP, Business Curriculum, Software Integration

\section{INTRODUCTION}

Enterprise Resource Planning (ERP) software organizes and manages a company's business processes by sharing information across functional areas. ERP provides a comprehensive information system for managing businesses. ERP integrates support for accounting, finance, customer relationship management, sales, human resources, logistics and distribution, purchasing, manufacturing and other corporate functions into single software system. In the recent past, ERP systems have become vital systems as firms try to improve their productivity and competitiveness. For medium and large US companies, approximately $60 \%$ of service firms and $75 \%$ of manufacturers have adopted an ERP system [6].

The worldwide market for ERP products is projected to increase from $\$ 20$ billion in 2002 to $\$ 31$ billion in 2006 according to an AMR Research study [1]. The global ERP market in manufacturing alone is projected to increase at a $5.7 \%$ compound annual growth rate from $\$ 9.1$ billion in 2003 to more than $\$ 12$ billion in 2008 according to a study by the ARC Advisory group [4]. While the marketplace for ERP in Tier 1 companies essentially reached saturation in 2002, there exists room for additional growth as Tier 1 companies add extra functionality to their existing ERP systems and the smaller Tier 2 and 3 companies look to duplicate the functionality that already exists in their larger competitors [5]. The EU expansion and midsize companies from Europe and elsewhere are fueling much of this growth. The number of midsize European companies which have fifty to a thousand employees is now estimated to exceed 100,000. The IT products and services market for these midsize EU companies exceeds about " $\$ 50$ billion per year" and their ERP adoption rate is expected to continue to grow [9]. The ERP market is already enormous and it is expected to get even bigger and more pervasive.

In addition, with vendor sponsored ERP initiatives for universities, it has never been easier or less expensive to include ERP software in business classes. The SAP University Alliances program and similar but smaller programs from other ERP vendors have made it much simpler to include ERP software into the classroom than it was only a few years ago. The SAP University Alliance program offers hosting services, support for curriculum development, faculty training, collaboration, and access to their Innovation Watch Web site that helps to ease the burden of integrating SAP software into business classrooms.

Existing research on ERP usage by business schools consists of numerous case studies of universities describing their individual experiences while implementing ERP software into the business curriculum. This study takes a different approach. This research surveys a large number of AACSB accredited universities in the US to determine the incidence of ERP integration, which ERP modules were most popularly integrated, the level of difficultly experienced while implementing ERP, and the benefits of implementing ERP software into the business curriculum. A review of the literature is presented in the next section. The methodology of the survey is followed by an analysis of results and the conclusions from the study. 


\section{LITERATURE REVIEW}

Traditional supply chain management (SCM) software represents an early and ongoing attempt to integrate several business processes into a single large software package. SCM software controls the flow of goods, services and information among the supply chain partners including the suppliers, producers, distributors and customers. As the supply chain modules of ERP packages have improved, there has been a gradual market shift towards using ERP software to manage the supply chain instead of SCM software packages that specialize in supply chain planning and warehouse management. Albright [1] states that companies are moving towards using supply chain ERP packages from PeopleSoft, SAP and other major ERP vendors. He believes that previously, specialized SCM software packages used to serve clients better than the more generalized ERP packages. Recently the supply chain modules of ERP packages have begun performing much better and they are gradually taking market share from the specialized supply chain software vendors. According to Albright, ERP systems help businesses by tying SCM with "financials, order management, promotion management, and master data management." Integration helps to manage assets, reduce cost of production and allows for easier inventory control. The ERP software market will continue to expand as more companies switch to using ERP in place of using traditional SCM software to manage their supply chains.

ERP vendors have even begun offering more specialized features in their software. The vice president of Oracle Corp's says that the latest version of its ERP system includes approximately "900 new industry-specific functions" [2]. Industry-specific functionality can help pharmaceutical firms that face a huge number of FDA requirements throughout all of their processes from development and testing, to manufacturing, packaging and shipping. Like many other industries, pharmaceutical firms have found industry-specific ERP systems to be very useful because they provide better documentation facilities, inventory tracking systems, and "key sales and invoicing functions" [2]. Specialized ERP software packages represent an additional opportunity for ERP vendors to expand into new markets.

An important reason why supercenters are so popular is because they provide the convenience of one-stop shopping for nearly all of our needs. Wal-Mart covers most aspects of our shopping needs and gradually has taken market share from local specialized businesses. Similarly ERP packages offer modules for most of the software needs of businesses and ERP is slowly taking market share from smaller more specialized packages. Even universities are being influenced by ERP software. Living in the enhanced information age with high speed internet connections creates an environment where college students come to campus expecting access to their grades, records and other important information as well. Student portals in universities around the world are now serving as onestop data shops for students. These portals are not only for providing grades anymore, they also serve to access information about tuition, tax credit, and many other confidential services. ERP systems have hastened the formation of these portals. Recently Purdue university adopted a SAP product to integrate its business processes and to serve its " 68,000 students on four campuses" through a "one university-wide system that is flexible, efficient, and user-centric" [8].

This paper discusses how universities have integrated ERP software into the business curriculum to better serve their students. The next section of the paper discusses the research methodology used for this study.

\section{METHODOLOGY}

\section{Questionnaire and Subjects}

A pilot survey was developed and disseminated to 20 universities known to use ERP software in their business classes. This survey asked questions concerning which ERP package was being used, how extensively it was being used in the business curriculum, and how difficult it was to implement ERP into their classes. As a result of this pilot study, the survey was revised. Specifically, the list of ERP vendors being used was modified as vendors were both added and removed. In addition, the list of modules being used in business classes was also updated.

The revised survey was sent to 408 AACSB accredited schools of business in the USA. The survey was addressed by name to the dean of the school of business at these 408 universities. None of the surveys were returned as undeliverable. The researchers received 107 usable surveys for an overall rate of return of about $26.2 \%$.

\section{ANALYSIS OF RESULTS}

The survey requested no demographic data on the respondents so the analysis can not be broken down by factors like size of university, size of the business 
school or region of country. The researchers wanted the respondents to have complete anonymity in their answers, so we requested no demographic data that can sometimes be used to identify individual responses.

The survey requested whether the university currently used ERP software in their business class, and if did not, did they have plans to do so within the next five years. The results were surprising. Although as one might expect, ERP software was not utilized by the majority- $56.07 \%$ of business schools-its frequency of use greatly surprised the researchers. Currently over a quarter, $27.10 \%$, of the universities are using ERP software in their business classes. We also found startling that nearly $16 \%$ of the universities are planning to incorporate ERP into their class within the next 5 years. See the results given in Figure 1.

\section{ERP Usage Among Sample Schools}

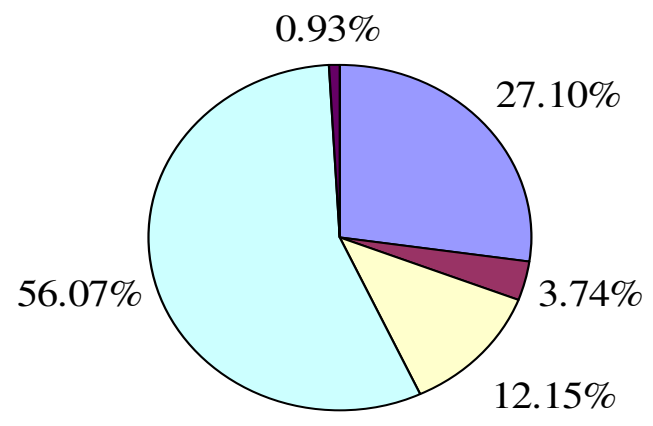

$\square$ Currently Using ERP

Currently do not use but plan to use within next year

$\square$ Currently do not use but plan to use within 1 - 5 years

$\square$ Currently do not use and no plan to use within 5 years

$\square$ Gave up using ERP

Figure 1. Frequency of ERP Software Usage in Business Classes

The researchers were interested in exploring further the total percentage of schools that were favorably inclined to use ERP software in their business classes. Combining those schools that currently use ERP software with those who plan to do so within 5 years leads to an overall figure of nearly $43 \%$ of the responding universities either using or expressing an interest in using ERP software in the business classes in the near future. Although this is the first study to document the overall usage of ERP software in business classes, the researchers were very shocked and pleased by this result.

The researcher asked those schools utilizing ERP in their classes which ERP package they had chosen to implement. The strength of the SAP University Alliance program coupled with the fact that SAP is the clear ERP market leader helps explain why SAP was chosen by approximately $56 \%$ of the universities who had used ERP software in their business classes. SAP was the clear leader with PeopleSoft/J.D. Edwards and Oracle finishing second and third with $22 \%$ and $18 \%$ respectively. The results on the ERP vendor distribution are not overly surprising given that SAP, PeopleSoft and Oracle together controlled approximately $63 \%$ of the worldwide ERP market, with market shares of $36 \%, 14 \%$ and $13 \%$ respectively according to a 2002 AMR Research study [1]. See Figure 3 for additional details on the ERP vendor distribution.

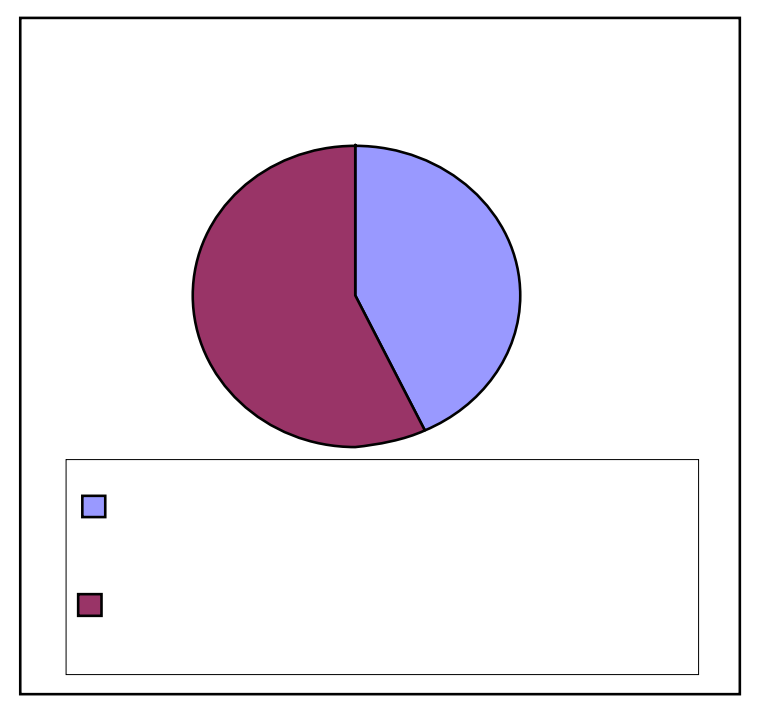

Figure 2. Overall Interest in Incorporating ERP in Business Classes 

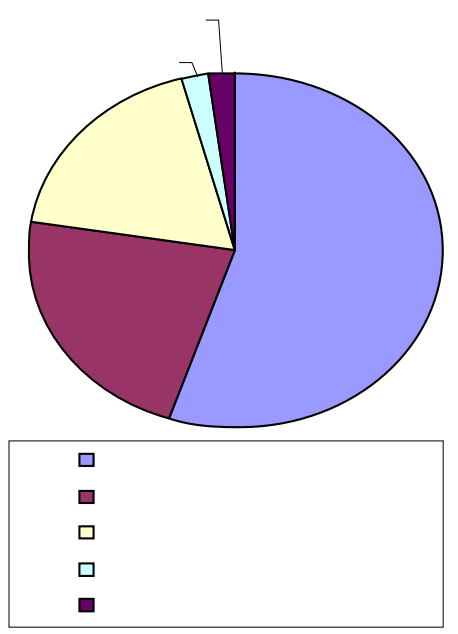

Figure 3. Vendor Distribution
The survey also asked the respondents to identify all of the ERP modules used in the business curriculum at their university. The supply chain/operations module was the most frequently integrated into business classes. This was not surprising given the inherent popularity of almost anything related to the study of supply chain concepts. Also not surprising was the fact that the accounting module was used second most with the marketing/customer relationship management module trailing in third place. The most surprising result was that the IS module only tied for fourth place with the finance module. Given the rapid increase in implementing packaged, off-the-shelf software systems in businesses worldwide, the researcher felt that there would have been a higher rate of interest by the IS area. The results on module usage are shown below in Figure 4.

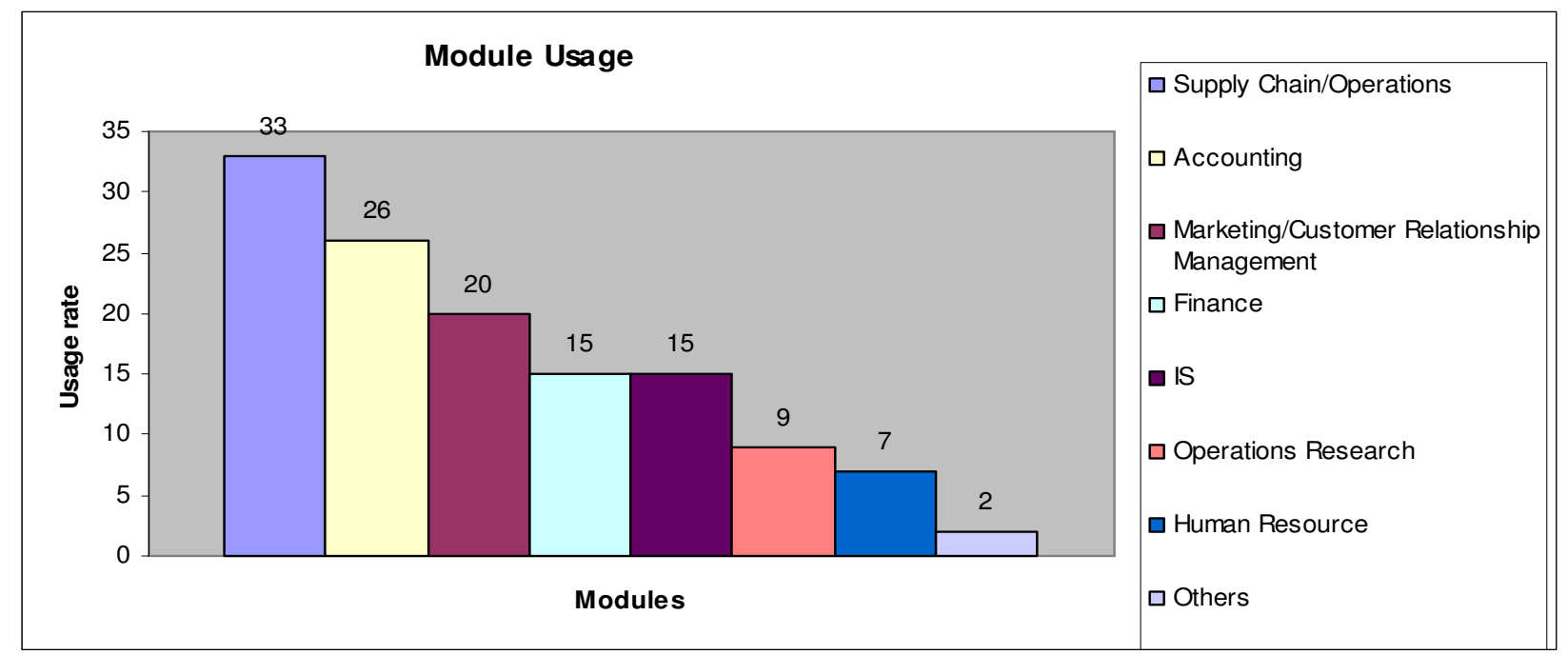

Figure 4. ERP Module Usage in Business Classes

The researcher asked for the degree of difficulty experienced to implement ERP software into the business curriculum. Common belief holds that ERP software implementations are often extremely challenging. For example, Rowe Furniture, Inc.'s blames a SAP R/3 software implementation for making changes to its manufacturing process that left it unable to keep up with customer demand. Rowe announced a $\$ 149,000$ loss for the first quarter of 2005 while it made a $\$ 72,000$ profit in the same quarter of the previous year while using its old system [7]. Moreover, FoxMeyer Drug, a \$5 billion pharmaceutical company, recently filed for bankruptcy citing problems that they claim were generated by a failed ERP system which created excess shipments resulting from incorrect orders. In addition, Dell Computer scrapped their ERP system claiming that it was not flexible enough to handle their expanding global operations [10]. Thus, the researcher were surprised to find that implementing ERP into business classes was most frequently described as relatively difficult instead of extremely difficult. In particular, $46 \%$ found the implementation to be relatively difficult while $20 \%$ found it to be extremely difficult. We were pleased to find that $11 \%$ of the respondents found it relatively easy to implement ERP into their business classes. The SAP University Alliances program has tried to ease the burden of implementing SAP into business classes and our research suggests their efforts may be working. These results are shown in Figure 5. 


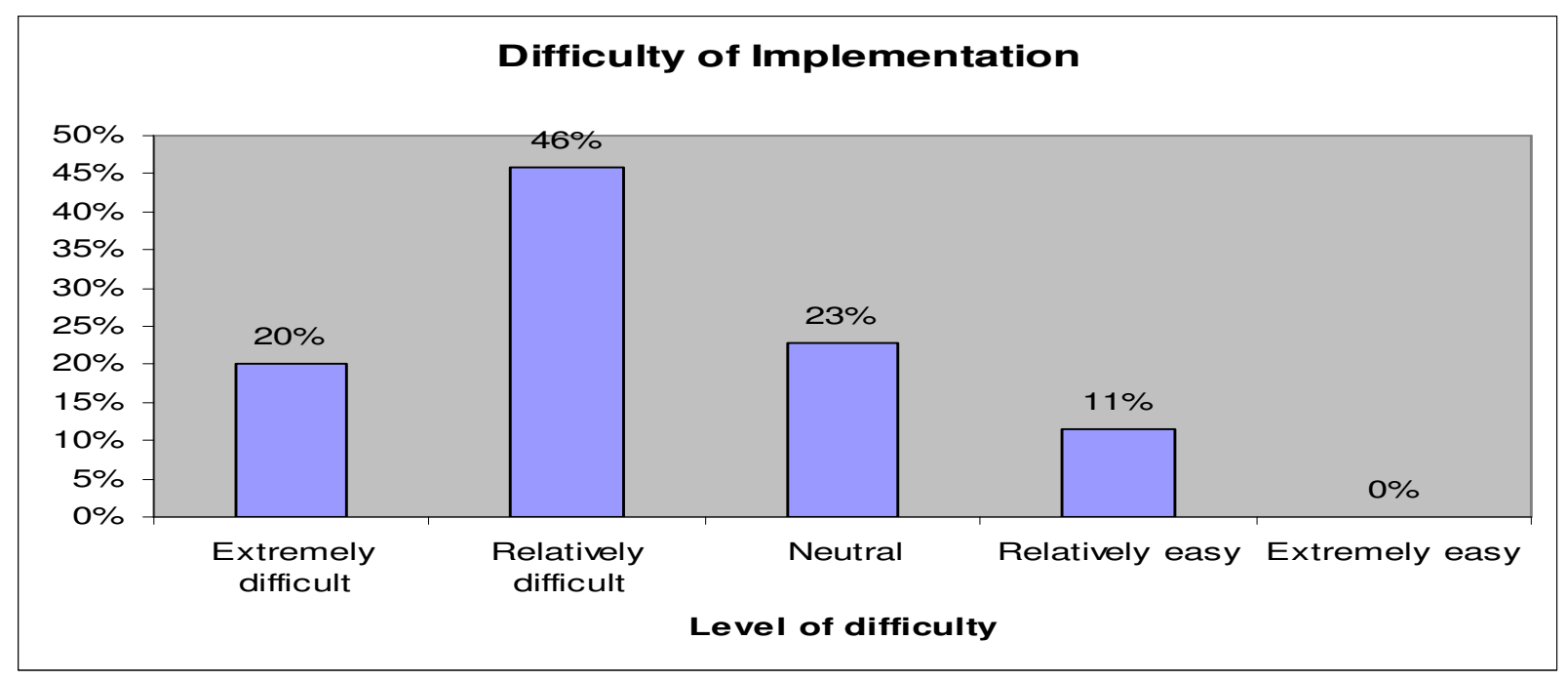

Figure 5. Difficulty Implementing ERP Software in Business Classes

The researchers wanted to determine what advantages were experienced by implementing ERP software in business classes. We asked an openended question requesting the respondent's opinions on what was the greatest benefit derived by implementing ERP software into their curriculum. Although the responses were varied, we found the following advantages were mentioned most frequently: focuses on business processes; integrates across functional areas; exposes students to current industry practice; benefits employers; attracts new employers to university; engages student interest in learning. Since we noticed similar responses in our pilot study, we included a question asking the respondents their opinions on job placement success. We were not surprised to find that more than two thirds of the respondents observed greater placement success for their student using ERP. These results are summarized in Figure 6.

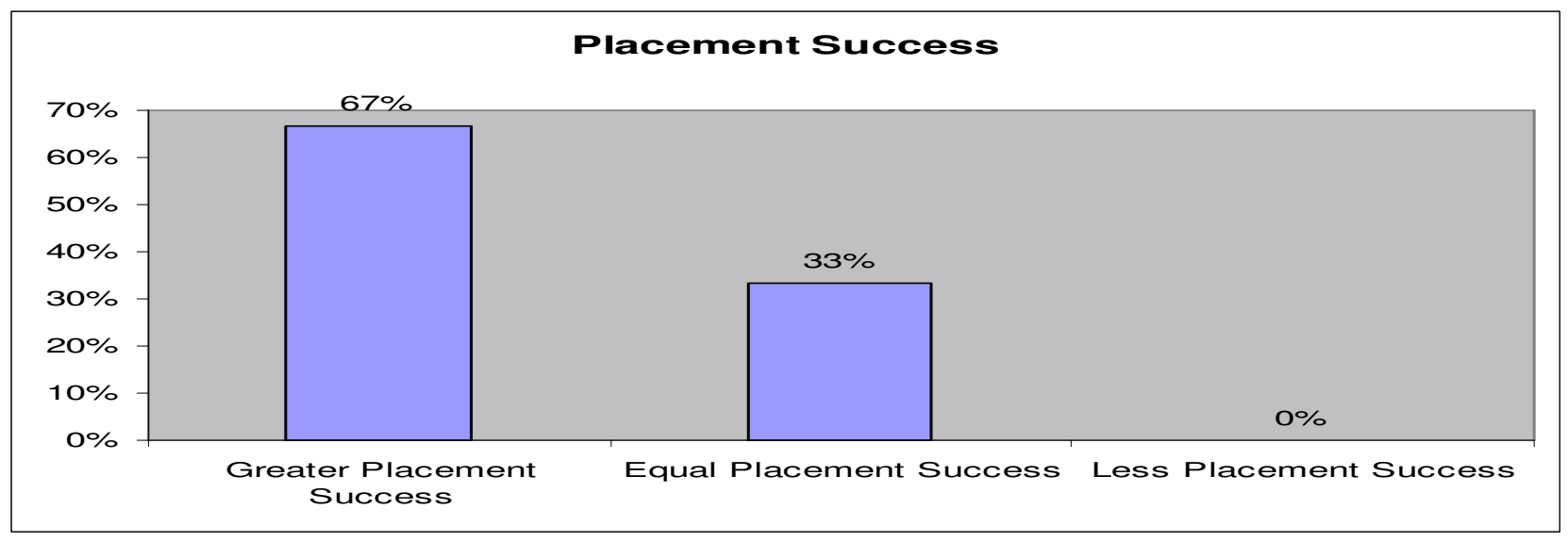

Figure 6. Job Placement Success after ERP Implementation

The researchers also asked an open ended question to detail the largest disadvantage experienced from implementing ERP into the curriculums. The responses most stated were additional work for faculty creates resistance; initial cost is high; takes time to integrate into classes; lack of pre-defined labs 
(recently decreasing due to curriculum support now provided by the biggest vendors such as SAP); errors occurring initially are mystifying; students must deal with the complexity. Most of these issues were predictable difficulties facing anyone, including faculty, attempting to use a new and complex ERP system.

\section{CONCLUSIONS}

Two major results were revealed by our study. First, over $40 \%$ of the business schools surveyed have already implemented or are on their way to implementing ERP software in their business curriculum. Second, over two thirds of those responding felt that implementing ERP software into business classes produced students who enjoyed greater placement success. Since implementing ERP software into classes was not as difficult as popularly believed and it is getting easier with each passing year, the researchers strongly encourage other universities to do so as it benefits both their students and employers.

\section{REFERENCES}

1. Albright, B. (2004). Assessing ERP software. Frontline Solutions, 5(8), 18-23.
2. Bartholomew, D. (2004). Finding the right fit. Industry Week, 253(6), 35-39.

3. Burton, J. (2005). One-stop data shop. University Business, 8(10), 36-40.

4. ERP market projected to gain from EU expansion. (2004). Control Engineering, 51(6), 15.

5. Industrial ERP: Poised for growth? (2002). Modern Materials Handling, 57(3), 15.

6. Scott, F \& Shepherd, J. (2002). The steady stream of ERP investments. AMR Research Outlook, August 26, 2002.

7. Songini, M. (2005). Difficult ERP rollout slows furniture maker. Computerworld, 39(18), 12.

8. Muscatello, J.R., Small, M.H., \& Chen, I.J. (2003). Implementing enterprise resource planning (ERP) systems in small and midsize manufacturing firms. International Journal of Operations \& Production Management, 23(8), 850-871.

9. Van Everdingen, Y., Van Hillegersberg, J., \& Waarts, E. (2000). ERP adoption by European midsized companies, Communications of the ACM, 43(4), 27-31. 